\title{
Antifungal Activity of Lactic Acid Bacteria, Isolated from Bulgarian Wheat and Rye Flour
}

\author{
Etem Sevgi and Ignatova-Ivanova Tsveteslava \\ Department of Biology, University of Shumen, Shumen 9712, Bulgaria
}

Received: December 25, 2014 / Accepted: January 3, 2015 / Published: January 30, 2015.

\begin{abstract}
The economic losses and the health hazards of the mycotoxins produced by spoilage fungi are the main concerns of the food industry. The spoilage of bakery products by fungi is more common in countries with a high humidity and temperature. About $5-10 \%$ of food production is spoiled by the growth of yeast and fungi in food materials. Similarly, in Western Europe, the growth of the spoilage fungi of bread is estimated to reach more than 200 million Euros per year. The history conditions of the food can be a major factor in determining any fungal spoilage - for example, stored and processed foods are more sensitive to spoilage when compared with fresh and prepared foods. Lactic acid bacteria isolated from Bulgarian wheat and rye flour were used in the present study to check their antifungal properties against pathogenic yeast and fungi imperfecta using standard disc diffusion method in vitro. A broad spectrum of antifungal activity of the six newly identified as $L$. plantarum strains e Ts1, Ts2, Ts3,Ts4 and Ts5, and $L$. helveticus Ts6 was estimated. Our in vitro studies were performed with wheat and rye sourdough, in order to simulate a real product and to assess the bio-protective potential of the tested lactobacilli. The used test-cultures are representatives of carcinogenic, toxigenic, deteriorative and allergenic fungi from the genera Aspergillus and Penicillium. The all tested strains completely suppress the growth of against C. glabrata 72. Strains L. plantarum Ts1 and Ts 3 completely suppress the growth against $S$. cerevisae. While, in the sample with L. plantarum strains e Ts1, Ts2, Ts3,Ts4 and Ts5, and L. helveticus Ts6, a retarded and weak growth of A. niger and $P$. claviforme was observed. However, the spore germination and the colony growth started only on the fifth day of the mould lactobacilli co-cultivation, which also should be considered as a good result. In this study six isolates Ts1,Ts2, Ts3, Ts4, Ts5 and Ts6, from the traditional Bulgarian wheat and rye flour have been identified as L. plantarum and L. helveticus and characterized as cultures with promising antifungal activity. Obtained results from the combined molecular identification (16S rRNA gene sequencing) approach contribute to give new data on the microbial biodiversity of this not well-studied niche. The antifungal activity of our new isolates, identified as L. plantarum and L. helveticus, seems to be a promising advantage of these six strains, suggesting their potential applications in different food technologies. However, more experiments have to be conducted to clarify the nature and the mechanisms of the reported antifungal activity and they are still in progress. The combination of dairy origin and strong inhibitory activity of the lactobacillus strains is a prerequisite for their possible application as starters and/or bioprotective antifungal adjuncts.
\end{abstract}

Key words: Lactic acid bacteria, antifungal activity, Bulgarian wheat and rye flour, pathogenic yeast, fungi imperfect.

\section{Introduction}

Fungi have a profound biological and economic impact as food spoilage agents, decomposers, plant and animal pathogens [1]. Their ability to grow anywhere, on anything, makes them both beneficial and harmful recyclers of carbon and nitrogen. Fungal spoilage of food and feed is a common and global phenomenon

Corresponding author: Ignatova-Ivanova Tsveteslava, $\mathrm{Ph} . \mathrm{D}$., associate professor, research fields: lactic acid bacteria as probiotics products, prebiotics-utilization of lactic acid bacteria, exopolysaccharides, corrosion, isolating microorganisms from Antarctica. E-mail: radi_cvet@abv.bg.
[2]. In addition to the negative financial consequences, fungal spoilage of food and feed also poses a serious health concern. Fungal growth on food stuffs can result in the production of mycotoxins which are known to be toxic to human and animals $[3,4]$. The most widespread species of fungi that contaminate bakery products belong to the genera Aspergillus, Penicillium, Eurotium [5-7], Monilia, Mucor, Endomyces, Cladosporium, Fusarium and Rhizopus [8, 9].

LAB (Lactic acid bacteria) has traditionally been used as natural biopreservatives in food and animal 
feed, sauerkraut and silage. Their preserving effect relates mainly to the formation of organic acids and hydrogen peroxide, competition for nutrients and production of antimicrobial substances [10]. Biopreservation refers to extended shelf-life and enhanced safety of foods obtained by the natural or added microflora or their antimicrobial products [11]. The preserving capacity of bacteria naturally occurring in food has gained increasing interest during the recent years, due to consumers demand for reduced use of chemical preservatives. Moulds and yeasts are common spoilage organisms of food products, such as cheese. Benzoic acid and sodium benzonate are primarily used as antifungal agents as well as natamycin produced by Streptomyces natalensis [12]. However, moulds and yeasts are becoming resistant to antibiotics but also to sorbic and benzoic acids $[13,14]$. LAB may produce compounds with antifungal activity, such as proteinaceous compounds [15], phenyllactic acid, cyclic dipeptides [16] and hydroxylated fatty acids [17]. Bacteriocin-like substances and other low and medium molecular weight mass compounds produced by LAB have been reported as antifungal [18-20]. However, studies on the effect of LAB on fungi are complicated by the sensitivity of most fungi to metabolites, lactic and acetic acids [21].

In this paper, the antifungal activity of LAB isolates from Bulgarian wheat and rye flour were used to check their antibacterial properties against pathogenic yeast and fungi using standard disc diffusion method In vitro.

\section{Materials and Methods}

\subsection{Test Microrganisms}

Aspergillus niger, Penicillium claviforme, Saccharomyces cerevisae, Candida albicans 8673 and Candida glabrata 72 were obtained from the National Bank for Industrial Microorganisms and Cell Cultures, Sofia, Bulgaria. All the isolates were checked for purity and maintained in slants of Nutrient agar.

\subsection{Media}

They were maintained on PDA (Potato Dextrose Agar, Oxoid, Hampshire, UK) plates at $30{ }^{\circ} \mathrm{C}$ and subcultured on a monthly basis until sporulation. The spores were harvested after establishing a good growth rate of each of the fungal cultures and were filtered with sterile cotton filter, to avoid the presence of conidia and mycelia. The spore's suspensions in PDA (pH e 7.0) were adjusted to the final concentrations in the range of $10^{5}-10^{6}$ spores $/ \mathrm{mL}$.

\subsection{Lactic Acid Bacteria Isolates}

The LAB strains was isolated from Bulgarian wheat and rye flour. Molecular analysis in LAB was performed by molecular identification (16S rRNA gene sequencing) in GeXP Genetic analysis system (Beckman Coulter, USA) [22]. The strains cultivated in media of MRS (de Mann Rogosa Sharpe, Biolife 272-20128, Milano, Italia) in composition, per liter: Tween 80-1; pepton from casein-10.0; meat extract-8.0; yeast extract-4.0; $\quad \mathrm{K}_{2} \mathrm{HPO}_{4}-2.0$; sodium acetat-5.0; amonium citrate-2.0; $\mathrm{MgSO}_{4} .7 \mathrm{H}_{2} \mathrm{O}-0.2$ and $\mathrm{MnSO}_{4}-0.05 \mathrm{~g} / \mathrm{L}$. The $\mathrm{pH}$ of media was adjusted to 6.5 with $1 \mathrm{M} \mathrm{NaOH}$. The basic media was sterilized by autoclaving at $121{ }^{\circ} \mathrm{C}$ for 20 min, and carbohydrates (glucose-20g/L) supplemented were sterilized using $0.22 \mu \mathrm{m}$ filters (Manisart ${ }^{\circledR}$ ).

\subsection{Assay for Antifungal Activity}

Antifungal assay was performed by the well disc diffusion method using soft $0.8 \%$ agar. Agar medium was added to sterile Petri dishes seeded with $100 \mu \mathrm{L}$ of each test yeast and fungi strains. Wells of equal distance were dug on the seeded plates. Before the assays, the strains $\mathrm{LAB}$ were twice pre-cultured in MRS broth, for $24 \mathrm{~h}$ at $37{ }^{\circ} \mathrm{C}$. Exponential Lactobacillus cultures in MRS broth were used as inoculum for the antifungal tests. The plates were incubated at $37{ }^{\circ} \mathrm{C}$ for $48 \mathrm{~h}$. The antifungal activity was assayed by measuring the diameter of the inhibition zone formed around the well [23]. All 
experiments were performed in triplicate.

\section{Results and Discussion}

Following the classical microbial methods were isolated 10 strains from 4 different natural sourdoughs prepared from wheat and rye flour. The data show that $90 \%$ of the isolates are of the type L. plantarum and $10 \%$ are the type L. helveticus [22]. In the present study, the effects of LAB on five pathogenic fungi were evaluated.

The effects of LAB on the pathogenics fungi were summarized in Table 1.

Varying degrees of inhibition were detected against the isolates of Aspergillus niger, Penicillium claviforme, Saccharomyces cerevisae, Candida albicans 8673 and Candida glabrata 72.

The sensitivities of the test organisms to infusions were indicated by clear zone around the wells (Fig. 1).

The tested strains completely suppressed the growth of against $C$. glabrata 72 (Table 1). Strains of $L$. plantarum Ts1 and Ts3 completely suppressed the growth of $S$. cerevisae (Table 1 and Fig. 1d). While, in the sample with L. plantarum strains e Ts1, Ts2, Ts3, Ts4 and Ts5, and L. helveticus Ts6, a retarded and weak growth of $A$. niger and $P$. claviforme (Figs. 1a and 1b) was observed. However, the spore germination and the colony growth started only on the fifth day of the mould lactobacilli co-cultivation, which also should be considered as a good result. In the literature, most of the active antifungal strains in fermented milk products were related to the $L$. casei group [24]. The displayed strong ability to inhibit species of genus Aspergillus and Penicillium (Figs. 1a and $1 \mathrm{~b}$ ) is a good testimonial to the L. plantarum and L. helveticus isolates from sourdough since these moulds often show resistance [25] and the inhibition of their growth is usually a difficult task. In the experiments, it was found that the presence of six Lactobacillus strains, inhibit the $P$. claviforme growth (Fig. 1b).

There are limited published data on the inhibition of Penicillium spp. by L. brevis [26, 27]. Only a few papers report a broad spectrum of inhibitory effects of LAB against micromycetes [15, 16, 28]. Most of the studies revealed a strain-specific antifungal activity against species of one, maximum two major mould genera [29-31]. There are several reports on antifungal activity of LAB. Okkers et al. [19] found that L. pentosus exhibited fungistatic effects against Candida albicans. Lavermicocca et al. [32] reported the production of antifungal compounds by a sourdough L. Plantarum strain. The same was observed for Lactobacillus coryneformis $\mathrm{Si3}$ [28] as well as isolates of L. plantarum, L. coryneformis, Lactobacillus salivarius, Lactobacillus sake, E. hirae, and Enterococcus durans from various sources [15]. Ström et al. [16] also found that L. plantarum MiLAB 393 produced antifungal substances. Addis, Fleet, Cox, Kolak, and Leung [33] reported that LAB inhibited the growth at several yeasts with $L$. plantarum being active against $S$. cerevisiae and other yeast species. Durlu-Ozkaya, Karabizak, Kayali, and Essen [34] found LAB, such as L. plantarum, L. paracasei, subsp. paracasei and Lactobacillus lactis isolated from a Turkish traditional cheese to inhibit S. cerevisiae, several species of Candida, Torulopsis glabrata and

Table 1 Inhibition zones ( $\mathrm{mm}$ ), of lactobacilli isolated from Bulgarian wheat and rye flour.

\begin{tabular}{|c|c|c|c|c|c|c|}
\hline \multirow{2}{*}{ Target strains } & \multicolumn{6}{|c|}{ Zone of inhibition $(\mathrm{mm})$ by strains LAB } \\
\hline & L. plantarum TS1 & L. plantarum TS2 & L. plantarum TS3 & L. plantarum TS4 & L. plantarum TS5 & L. helveticus TS6 \\
\hline A. niger & $35.85 \pm 0.01$ & $33.66 \pm 0.19$ & $32.92 \pm 0.02$ & $32.49 \pm 0.02$ & $32.59 \pm 0.20$ & $33.28 \pm 0.15$ \\
\hline P. claviforme & $27.34 \pm 0.15$ & $26.81 \pm 0.17$ & $27.01 \pm 0.03$ & $26.35 \pm 0.02$ & $25.29 \pm 0.03$ & $26.10 \pm 0.21$ \\
\hline S. cerevisae & - & $7.85 \pm 0.03$ & - & $8.64 \pm 0.15$ & $10.23 \pm 0.19$ & $8.99 \pm 0.02$ \\
\hline C. albicans 8673 & $13.69 \pm 0.03$ & $17.58 \pm 0.01$ & $14.34 \pm 0.02$ & $12.55 \pm 0.17$ & $14.24 \pm 0.01$ & $18.27 \pm 0.19$ \\
\hline C. glabrata 72 & - & - & - & - & - & - \\
\hline
\end{tabular}

Data are presented as average values \pm standard deviation in $\mathrm{mm}$. 


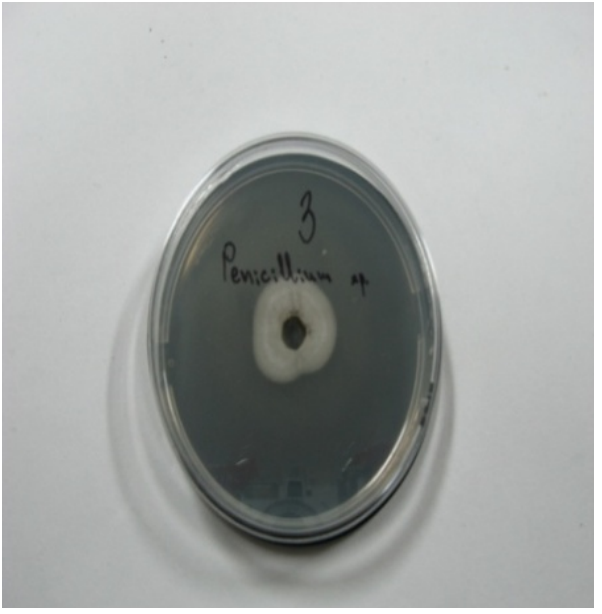

(a)

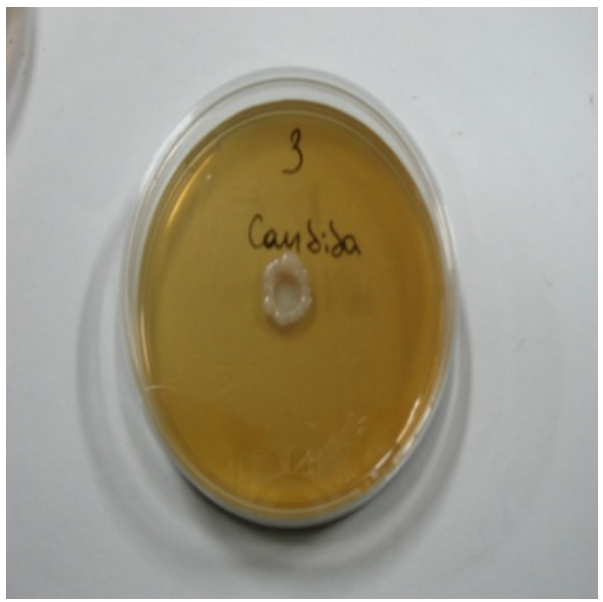

(c)

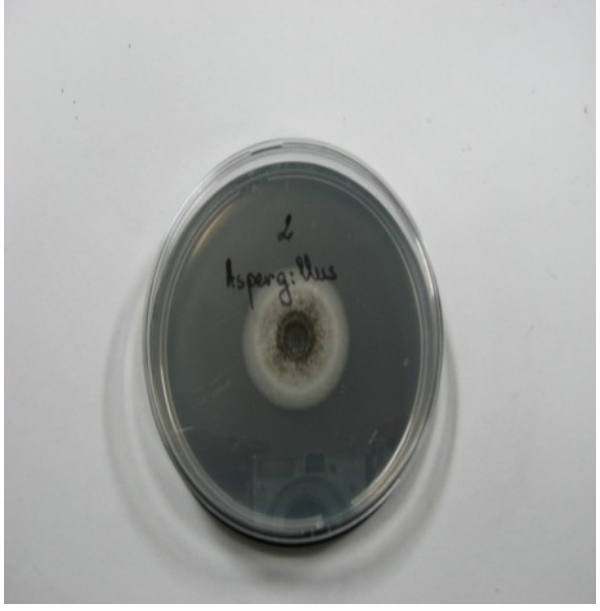

(b)

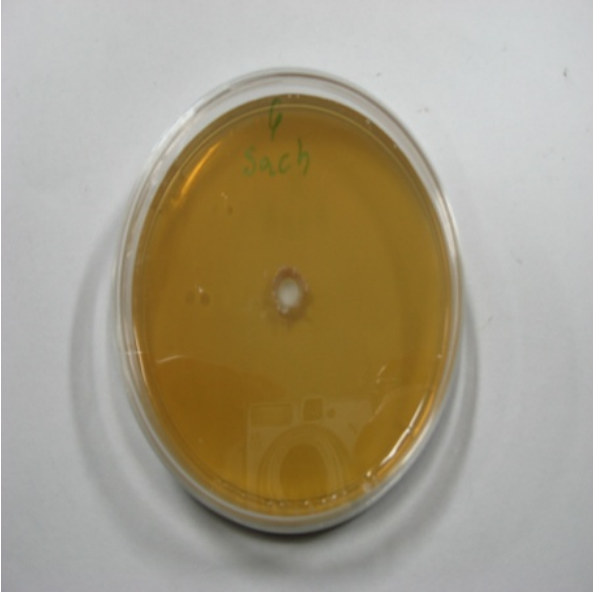

(d)

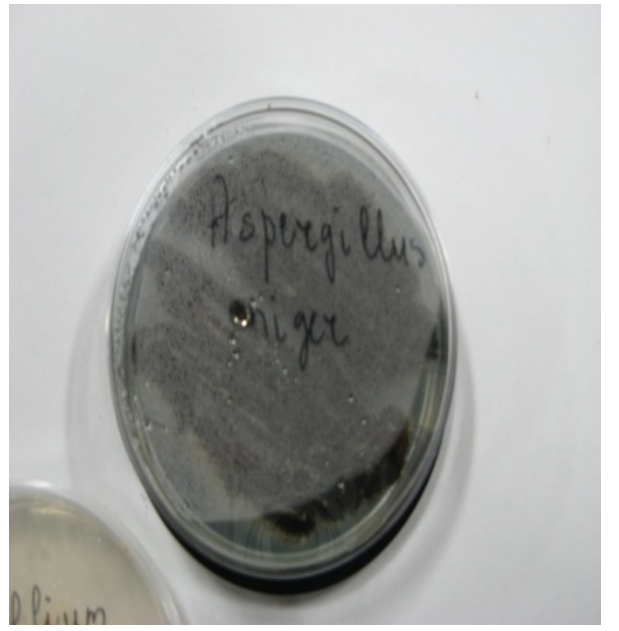

(e)

Fig. 1 Showing Zone of inhibition with LAB along without LAB as control after seven days. a) Strain $L$. plantarum Ts3 cultivated with $P$. claviforme; b) Strain $L$. plantarum Ts2 cultivated with $A$. niger; c) Strain $L$. plantarum Ts 3 cultivated with $C$. albicans 8673; d) Strain $L$. helveticus Ts6 cultivated with $S$. cerevisae; e) Control $A$. niger cultivated without LAB. 
Rhodotorula rubra, isolates from the same cheese. Several LAB isolates from sourdough bread cultures were screened for antifungal activity against a battery of moulds and the most inhibitory was L. paracasei subsp, tolerans [25]. Also, LAB with potential to eliminate fungal spoilage in foods were obtained from malted cereals [20].

\section{Conclusions}

In this study seven isolates Ts1, Ts2, Ts3, Ts4, Ts5 and Ts6, Ts7 from the traditional Bulgarian wheat and rye flour have been identified as $L$. plantarum and $L$. helveticus and characterized as cultures with promising antifungal activity. Obtained results from the combined molecular identification (16S rRNA gene sequencing) approach contribute to give new data on the microbial biodiversity of this not well-studied niche. The antifungal activity of our new isolates, identified as L. plantarum and L. helveticus, seems to be a promising advantage of these six strains, suggesting their potential applications in different food technologies. However, more experiments have to be conducted to clarify the nature and the mechanisms of the reported antifungal activity and they are still in progress. The combination of dairy origin and strong inhibitory activity of the lactobacillus strains is a prerequisite for their possible application as starters and/or bioprotective antifungal adjuncts.

\section{Acknowledgments}

The contributors express their gratitude for the funding by the project by Shumen University project RD 08-266/10.03.2015.

\section{References}

[1] Oranusi, S., Braide, W., and Oguoma, O. I. 2013. "Antifungal Properties of Lactic Acid Bacteria (LAB) Isolated from Ricinus Communis, Pentaclethra Macrophylla and Yoghurts." Global Advanced Research Journal of Food Science and Technology 2 (1): 1-6.

[2] Pitt, J. J., and Hocking, A. D. 1999. Fungi and Food
Spoilage. 2nd edn. Gaithersburg, M. D. Aspen publication.

[3] Kabak, B., Dobson, A., and Var, I. 2006. "Strategies to Prevent Mycotoxin Contamination of Food and Animal Feed: a Review." Crit. Rev. Food Sci. Nutr. 46: 593-619.

[4] Sweeney, M., and Dobson, A. 1998. "Mycotoxin Production by Aspergillus, Fusarium and Penicillium Species." Int. J. Food Microbiol. 43: 141-158.

[5] Abellana, M. L., Torres, V. S., and Ramos, A. J. 1997. "Caracterizatión of Differents Products from Pastries Industrial II." Estudio de la Microflora. Alimentaria 287: 51-56.

[6] Batish, V. K., Roy, U., Lal, R., and Grower, S. 1997. "Antifungal Attributes of Lactic Acid Bacteria e a Review." Critical Rev. Biotechnol. 17 (3): 209-225.

[7] Guynot, M. E., MarÍn, S., Setu, L., Sanchis, V., and Ramos, A. J. 2005. "Screening for Antifungal Activity of Some Essential oils Against Common Spoilage Fungi of Bakery Products." Food Science and Technology International 11: 25-32.

[8] Lavermicocca, P., Valerio, F., and Visconti, A. 2003. "Antifungal Activity of Phenyllactic Acid Against Molds Isolated from Bakery Products." Applied Environmental Microbiology 69: 634-640.

[9] Samson, R. A., Seifert, K. A., Kuijpers, A. F. A., Houbraken, J. A. M. P., and Frisvad, J. C. 2004. "Phylogenetic Analysis of Penicillium Subgenus Penicillium Using Partial B-Tubulin Sequences." Studies in Mycology 49: 175-200.

[10] Stiles, M. E. 1996. "Biopreservation by Lactic Acid Bacteria." Antonie van Leeuwenhoek 70: 331-345.

[11] Schnürer, J., and Magnusson, J. 2005. "Antifungal Lactic Acid Bacteria as Biopreservatives." Trends in Food Science and Technology. 16: 70-78.

[12] Davidson, M. P. 2001. "Chemical Preservatives and Natural Antimicrobial Compounds." In Food Microbiology: Fundamentals and Frontiers, edited by Doyle, M. P., Beuchat, L. R., and Montville, T. J. Washington: ASM Press.

[13] Brul, S., and Coote, P. 1999. "Preservative Agents in Food. Mode of Action and Microbial Resistance Mechanisms." International Journal of Food Microbiology 50: 1-17.

[14] Viljoen, C. B. 2001. "The Interaction Between Yeasts and Bacteria in Dairy Environments." International Journal of Food Microbiology 69: 37-44.

[15] Magnusson, J., and Schnürer, J. 2001. "Lactobacillus Coryniformis subsp. Coryniformis Strain Si3 Produces a Broad-Spectrum Proteinaceous Antifungal Compound." Appl Environ Microbiol 67 (1): 1-5.

[16] Ström, K., Sjögren, J., Broberg, A., and Schnürer, J. 2002. "Lactobacillus Plantarum MiLAB 393 Produces the 
Antifungal Cyclic Dipeptides Cyclo (L-Phe-L-Pro) and Cyclo (L-Phe-trans-4-OH-L-Pro) and 3-Phenyllactic Acid." Applied and Environmental Microbiology 68: 4322-4327.

[17] Sjogren, J., Magnusson, J., Broberg, A., Schnürer, J., and Kenne, L. 2003. "Antifungal 3-Hydroxy Fatty Acids FROm Lactobacillus Plantarum MiLAB 14.” Applied and Environmental Microbiology 46: 62-67.

[18] Niku-Paavola, M. L., Laitila, A., Matilla-Sandholm, T., and Haikara, A. 1999. "New Types of Antimicrobial Compounds Produced by Lactobacillus Plantarum." Journal of Applied Microbiology 86: 29-35.

[19] Okkers, D. J., Dicks, L. M. T., Silvester, M., Joubert, J. J., and Odendaal, H. J. 1999. "Characterization of Pentocin TV35b, a Bacteriocin-Like Peptide Isolated from Lactobacillus Pentosus with a Fungistatic Effect on Candida Albicans." Journal of Applied Microbiology 87: 726-734.

[20] Rouse, S., Harnett, D., Vaughan, A., and van Sinderen, D. 2008. "Lactic Acid Bacteria with Potential to Eliminate Fungal Spoilage in Foods." Journal of Applied Microbiology 104: 915-923.

[21] Bonestroo, M. H., Dewit, J. C., Kusters, B. J. M., and Rombout, F. M. 1993. "Inhibition of the Growth of Yeasts in Fermented Salads." International Journal of Food Microbiology 17: 311-320.

[22] Ignatova-Ivanova, Ts., Ananieva, M., Ivanov, R., Iliev I., and Ivanova, I. 2014. "Biodiversity of Lactic Acid Bacteria in Bulgarian Wheat and Rye Flour." J. BioSci. Biotech SE/ONLINE: 101-105.

[23] Muhialdin, B. J., Zaiton, H., and Nazamid, S. 2013. "Lactic Acid Bacteria in Biopreservation and the Enhancement of the Functional Quality of Bread." INTECH. Chapter 6.

[24] Delavenne, E., Ismail, R., Pawtowski, A., Mounier, J., Barbier, G., and Le Blay, G. 2012. "Assessment of Lactobacilli Strains as Yogurt Bioprotective Cultures." Food Control 30: 206-213.

[25] Hassan, Y. I., and Bullerman, L. B. 2008. “Antifungal Activity of Lactobacillus Paracasei spp. Tolerans Isolated from a Sourdough Bread Culture.” International
Journal of Food Microbiology 121: 112-115.

[26] Falguni, P., Shilpa, V. I. J., and Mann, B. 2010. "Production of Proteinaceous Antifungal Substances from Lactobacillus Brevis NCDC 02.” Int. J. Dairy Technol. 63 (1): 70-76.

[27] De Muynck, C., Leroy, A.I., De Maeseneire, S., Arnaut, F., Soetaert, W., and Vandamme, E. J. 2004. "Potential of Selected Lactic Acid Bacteria to Produce Food Compatible Antifungal Metabolites." Microbiol Res. 159 (4): 339-346.

[28] Magnusson, J., Streom, K., Roos, S., Sjeogren, J., and Schnürer, J. 2003. "Broad and Complex Antifungal Activity among Environmental Isolates of Lactic Acid Bacteria." FEMS Microbiol Lett." 219 (1): 129-135.

[29] Gerez, C. L., Torino, M. I., and Rollan, G. 2009. "Font de Valdez G. Prevention of Bread Mould Spoilage by Using Lactic Acid Bacteria with Antifungal Properties." Food Control 20 (2): 144-148.

[30] Gourama, H. 1997. "Inhibition of growth and mycotoxin production of Penicillium by Lactobacillus species." LWT e Food Sci Technol 30 (3): 279-283.

[31] Laitila, A., Alakomi, H. L., Raaska, L., Mattila-Sandholm, T., and Haikara, A. 2002. "Antifungal Activities of Two Lactobacillus Plantarum Strains Against Fusarium Moulds in vitro and in Malting of Barley." J. Appl. Microbiol. 93 (4): 566-576.

[32] Lavermicocca, P., Valerio, F., Evidente, A., Lazzaroni, S., Corsetti, A., and Gobetti, M. 2000. "Purification and Characterization of Novel Antifungal Compounds from the Sourdough Lactobacillus Plantarum Strain 21B." Applied and Environmental Microbiology 66: 4084-4090.

[33] Addis, E., Fleet, G. H., Cox, J. M., Kolak, D., and Leung, T. 2001. "The Growth, Properties and Interactions of Yeasts and Bacteria Associated with the Maturation of Camembert and Blue-Vined Cheeses." International Journal of Food Microbiology 69: 25-36.

[34] Durlu-Ozkaya, F., Karabizak, N., Kayali, R., and Essen, B. 2005. "Inhibition of Yeasts Isolated from Traditional Turkish Cheeses by Lactobacillus spp." International Journal of Dairy Technology 58: 111-114. 